\title{
PATRIMONIO: ENTRE LA TREGUA MELANCÓLICA Y UN LENGUAJE PARA LA DECLINACIÓN. LA TRANSFORMACIÓN URBANA DE MARÍA ELENA, NORTE DE CHILE ${ }^{1}$
}

\author{
Juan Carlos Rodríguez y Pablo Miranda ${ }^{3}$
}

\section{* InTRoducción}

Resumen

Este trabajo trata sobre la representación social de la crisis de los patrones estructurales y de los significados compartidos, así como de los elementos históricamente legitimados a través de las prácticas y relaciones sociales en María Elena, una ciudad salitrera en declinación situada en la II región de Chile. Se discute la transformación de las condiciones de trabajo y el vínculo con los trabajadores y familias, y la ruina material,

ya que a través de ella se expresa el cuestionamiento del futuro como proyecto vital. Todo ello se inserta en la transformación de una ciudad a campamento minero, en el que se comienza a instalar la noción de patrimonio. Vaciada la ciudad de los viejos conocimientos, de la vida familiar, la sociabilidad y el desuso de los inmuebles de mayor significación, ésta comienza a transformarse únicamente en un parque temático.

Palabras claves: patrimonio - campamento minero - parque temático memoria - representación social.

Abstract

This paper deals with the social representation of the crisis of the patterns of shared meanings and also of the historical elements legitimized through social practices and relationships in Maria Elena, a nitrate city in decline (Northern Chile). The focus of discussion is the transformation of working conditions and the link with the workers and families, and material ruin, since it is expressed through the questioning of the future as a vital project. This is inserted into

the transformation of a town in a mining camp, where begins to install the notion of heritage. Emptied the city of the old skills, family life, sociability and disuse of buildings of greater significance, it only begins to become a thematic park.

Key words: heritage - mining camp - thematic park - memory - social representation.

Recibido: enero 2010. Aceptado: agosto 2010.
La desnudez de los desiertos ofrece una importante posibilidad de imaginación y experimentación que, como ha señalado Martín (2007: 15), puede ser apreciada como "una hoja de papel en la tabla de dibujo"; es decir, una suerte de punto de partida y de principio básico en el cual las trazas de la imaginación pueden lograr y desarrollar cierto "ornamento". Es, como dice el diseñador y antropólogo, un lugar de cierta experimentación desde el cual los "propósitos primeros" pueden generar proyectos más complejos y verse sobrecargados, o crear variantes para ser aplicadas en otros espacios. Frente a la tabla de dibujo, tenemos a constructores de lenguas, territorios y obras.

La figura del desierto de Atacama, en su expresión citadina, a partir de la construcción de las "ciudades del salitre" -como llama Garcés (1999) a Chacabuco (1924), María Elena (1925-26) y Pedro de Valdivia (1931) - precipita precisamente la idea de la tabla de dibujo. Las ciudades del salitre -y también las del cobre (Garcés et al. 2007) - revelan un arte de imaginar y hacer ciudad por parte de empresas que, más allá de lo arquitectónico, un elemento diferencial y que las transforma en únicas, generó el diseño para establecer una relación emocionalmente segura para sus habitantes, activando con el paso del tiempo la creación de universos culturales de gran fuerza e importante identificación. Con ellas, en su forma de company town, pueblo industrial o ciudad obrera, con sus divisiones funcionales (instalaciones industriales, habitaciones y servicios para la vida cotidiana) decanta un territorio perteneciente al reino

\footnotetext{
1 Este trabajo es producto del Proyecto FONDECYT 1060092: "María Elena, cambio y reestructuración cultural. Una cartografía antropológica de sus marcadores".

2 Escuela de Diseño, Facultad de Arquitectura, Universidad de Valparaíso. Exequiel Fernández 9o, depto. 1309, Ñuñoa, Santiago, CHILE. Email: memoriasur@gmail.com

3 Escuela de Arte, Pontificia Universidad Católica de Chile. Jaime Guzmán Errázuriz 330o, Providencia, Santiago, CHILE. Email: pmirandb@uc.cl
} 
mental del habitante; un modelo para ejercer autoridad y de autocontención, un modelo de entender la entretención y de convivencia para delinear y proyectar la vida que tiene profundos impactos sociales, económicos y territoriales, como es el caso del desarrollo de la vivienda obrera.

El reclutamiento de los trabajadores otorga el beneficio de la exclusividad como miembro de la empresa y la ciudad, lo que se constituye en una cadena de valor que permite el acceso a bienes y servicios garantizados. En ello descansa una intensa sociabilidad que se construye entre iguales, lo que en términos de Castoriadis (1981) ofrece la singularidad de lo propio, que marca los cambios y transiciones, y sobre todo, manifiesta un imaginario que orienta y dirige la vida social.

Las ciudades del salitre definen un claro patrón de asentamiento al concentrar de manera eficiente actividades productivas y sociales. Son capitales, mano de obra, maquinarias, residencias, recreación, equipamientos, autosuficiencia y una contenida vinculación con el exterior. Todo ello constituye la marca de María Elena, la sobreviviente de esta experiencia urbanística de concepción utópica. Sus habitantes tuvieron en ella una doble dependencia con las administraciones: físicamente, por el aislamiento de la ciudad, y una relación ideológica y simbólica. Este universo social y cultural, del mismo modo como se experimentó en Pedro de Valdivia y Chacabuco, fijó una condición de autonomía y de distancia no solo física con las urbes mayores, sino también emocionalmente de lejanía y de distinción frente a aquellas, a través de los servicios y la seguridad que ofrecía (Figura 1).

Decantados en el tiempo, estos universos culturales autosuficientes y autocontenidos, pensados como imaginarios y complejos culturales, deberíamos decir etnológicamente que en tanto habitantes, los eleninos "aprendieron" este lugar, en el curso de generaciones, como si estuviesen aprendiendo a leer un libro. De modo general, tras décadas de aprendizaje, este leer y descifrar claves, se transforma en una forma de develar un lugar en el cual se puede comprender lo que ocurre en términos presentes. Pero, también, donde se establece cierto control sobre lo que ocurrió en términos pasados y sobre lo que ocurrirá como expresión de futuro en el lugar que se habita. Esta lectura, indica un aprendizaje tanto en cuestiones asociadas al comportamiento, a las relaciones sociales y a cómo se vincula este lugar con otros.

Así, para este estudio de caso, una perspectiva antropológica se relaciona biográficamente con el cómo se hace lugar, se proyecta lugar, se experimenta lugar y cómo éste se transforma de acuerdo a las vivencias de las generaciones; por lo que el espacio debe ser estudiado a través de los sentidos y significados que las distintas personas le otorgan (Gomuchian 1991; Augé 2008).

En este espacio comprimido es donde circula la palabra, donde se expresa lo relacional, lo dialógico, porque es parte de un ámbito de semejanzas y referencias comunes que dan paso a la "comunidad imaginada" (Anderson 2002). También, se da la relación con las materialidades en sus usos y como referencias que dibujan la ciudad en la memoria. De manera genérica, en sus redes, y apreciados estos espacios urbanos únicos como mapas mentales, aparecen las estructuras cognitivas y sociocognitivas en los individuos y sociedades para hacerse cargo del lugar, el territorio, la naturaleza, el país y el mundo. En ellos, que son auténticos marcadores de sus prácticas y elementos de diferenciación, asoma la mirada particular y pueden apreciarse elementos históricos, culturales y estéticos, reforzados sobremanera al tratarse de una ciudad privada, $y$ cuya existencia depende de la monoproducción.

A partir de los procesos de privatización que se originan en 1988 dando fin al sentido organizador y protector de la company town - para los casos de María Elena y Pedro de Valdivia, que son las últimas ciudades del salitre-, se inicia una progresiva desestructuración de la ritualidad y las certezas básicas con las cuales se configuró la vida interior, la lectura del exterior y el paisaje. Muchos de sus habitantes tuvieron que plantearse un futuro intolerable para la imaginación, cambiar la vida, reestructurar los proyectos o empezar de nuevo. La abrupta separación de la segura ciudad de la infancia (física y psicológica, o la combinación de ambas), se ha convertido para muchas familias en una activa angustia por vivir en el día a día, porque se invirtió la vida en esa relación de pertenencia que tempranamente ofreció cierta movilidad social y seguridad.

Desde la privatización empresarial en María Elena, las familias ya no son necesarias para la productividad y rentabilidad, y los habitantes deben empezar a reorga- 


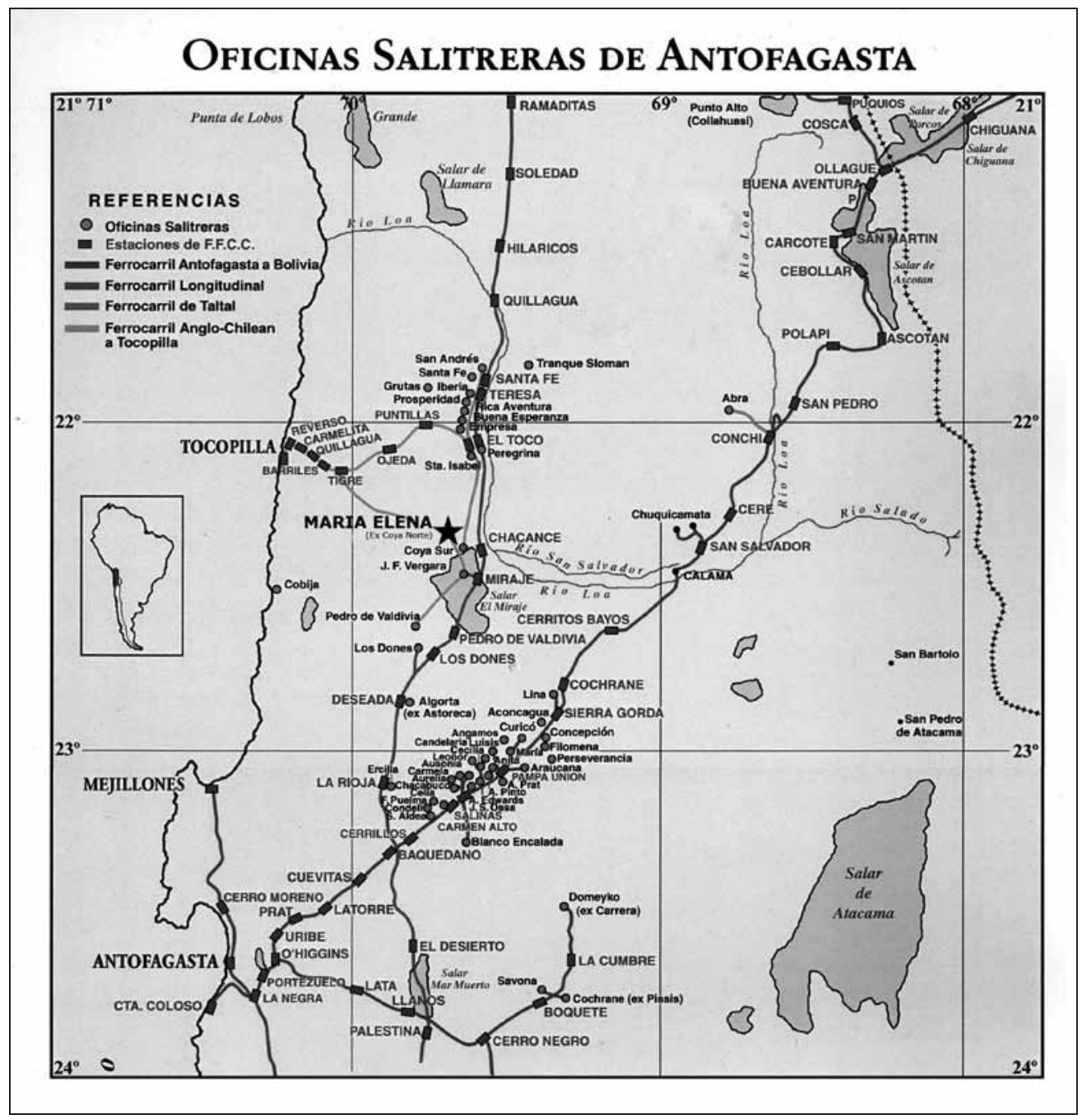

Figura 1. Mapa de localización de María Elena y las principales oficinas salitreras de la región de Antofagasta, en el norte de Chile.

nizar los gestos que moldean la vida cotidiana y pensar en la escisión del maridaje entre trabajar en la pampa y habitarla (Mandujano 2007 Ms; Rodríguez 2007; Rodríguez y Miranda 2008).

El fin de la company town, la privatización y las expectativas empresariales han instalando tres cuestiones a resolver en las últimas dos décadas:

1) Qué hacer con la ciudad de María Elena que pertenece en su totalidad a la empresa SOQUIMICH (SQM) y con la inversión ahí realizada como activo, ya que la empresa no es por definición rentista.
2) Cuáles son los usos eficientes que se le puede dar al complejo urbano de acuerdo a los propios imperativos empresariales.

3) Qué hacer con su gente, especialmente con aquella no ligada directa o indirectamente a actividades productivas, con aquella que está en su etapa postproductiva, o aquella desafiliada por obsolescencia de sus experticias en un marco laboral que demanda calificación (Rodríguez y Miranda 2008).

Estas preguntas y sus posibles respuestas son experimentadas como una combinación de inseguridad, nostalgia, 
pragmatismo e incertidumbre por parte de las familias, y se dan en un contexto donde los más afectados son los antiguos habitantes, que viven llenos de recuerdos y añorando el pasado de una ciudad que ya no existe más allá de lo guardado en sus memorias.

\section{* El declinar de una ciudad}

En el curso de los últimos 10 años, hemos podido apreciar un importante declinar de la palabra y de los recursos retóricos empleados por los habitantes de María Elena, que coincide, por una parte, con la tendencia al despoblamiento de la ciudad como expresión de la desurbanización que sufre, lo que la transforma en términos de expectativas en un emplazamiento para trabajar y no para vivir. Por otra parte, con una nueva relación de las personas con el espacio, producto de la imposición de un modelo distinto de relaciones laborales sustentado en la flexibilización numérica y funcional de la plantilla, y la externalización de servicios, lo que se traduce en una no necesaria coincidencia entre residir y trabajar en la ciudad. Como consecuencia de ello, la ciudad pierde habitantes y familias, se ha quedado sin masa crítica, y sin profesionales asociados afectiva y emocionalmente a ella. De este modo, lo que ocurre en cuanto a decisiones que la afectan como urbe y espacio de sociabilidad, llegan desde fórmulas no elaboradas por sus habitantes, sino como condición directa de decisiones empresariales.

Con estas determinaciones, ya nadie en la actualidad habla como "alcalde", como actor que sostiene la carga dramática de la escena urbana, como el que indica aquello que de manera general y específica se debe o debía hacer, lo que era una cuestión recurrente y que expresaba una preocupación y expectativa sobre y en la ciudad de todo residente comprometida con ella. Así, en este empobrecimiento, crepita menos la niñez en sus habitantes, en medio del polvo, el cine, el cuadro blanco, los desfiles de caballería, las fiestas y galas. Toda esa retórica y experiencia que es representación, ha empezado a migrar hacia el exterior de María Elena con la salida de familias y la entrada de muchos trabajadores externos no vinculados a ella, al trabajo en la pampa y a la explotación del nitrato.

Esta situación asociada al nombrar, recordar, identificar, fabular y representar, llena de documentos (objetos de co- lección) y frases hechas, constituía una importante forma de justificación de la propia presencia realzando el valor del habitante, como también marcando afectiva y simbólicamente la ciudad y legitimando la necesidad de ciertas prácticas presentes y futuras para contener el declinar y la salida de los grupos familiares. Pero, a pesar del importante deterioro material y existencial percibido, que para algunos corresponde francamente a abandono frente a la ciudad luminosa que aún vive en la memoria de algunos, el fenómeno compartido de la vida en común -expresado en diálogo, conflicto e influencias-, tenía la función reconocida de proteger el equilibrio simbólico frente a la acelerada precipitación del cambio en términos sociales y materiales, y de dar cierta continuidad a la memoria.

Estas debilitadas apreciaciones deben ser consideradas como una importante reserva y construcción "comunicativa" y una "representación social", y en ese sentido se transformaban en formas colectivas (Banchs et al. 2007), porque no es posible repensar los acontecimientos del pasado personal sin disertar sobre ellos (Casquete 2008: 110). Esta elaboración discursiva y exégesis sobre la diferencia siempre positiva de María Elena y su gente, como imaginario social, expresaba "el poder figurativo de la imaginación, el cual excede los límites del mundo sensible" (Lozada, cit. en Banchs et al. 2007: 51), lo que ayudaba a estructurar, proyectar y dar continuidad a la comunicación intergeneracional, a la memoria histórica y a la experiencia social de los habitantes de la ciudad industrial.

La debilidad de la comunicación y la desmejorada expectativa del permanecer en María Elena como parte de un proyecto vital, define el lugar que ocupa el pasado en las representaciones que los habitantes se hacen de él; y, paralelamente, la relación que los habitantes tienen respecto de él. Para los mayores, solo nostalgia; para los más jóvenes, cada vez menos crédito o un mundo más anecdótico.

De este modo, con el despoblamiento general de la pampa, el ser elenino se constituye en la marca de los últimos habitantes de la pampa y los últimos salitreros en habitarla, especialmente después del cierre de Pedro de Valdivia, que constituía su alter ego. Esta imagen, que es afirmación de identidad, entra en un derrotero donde la comunicación y el proyecto vital van irreversiblemente en retirada, en la medida que lo que queda de ciudad se refugia en la arquitectura más que en el espacio de interac- 
ción, ya que coexiste empíricamente con un campamento minero que puede funcionar al margen de ésta, e incluso prescindiendo de su existencia.

La identidad citadina como cultura se debilita en sus claves, y la comunicación revela estrechez, presentándose como una voz que se apaga. Etnológicamente, cuando lo descrito no está en lo inmediato y cotidiano, se aprecia en franca retirada o no coincide con los hechos, podemos hablar del fin del espacio público, de lo vivido en común, de la relación cara a cara, porque se han destripado "las políticas históricas de la proximidad, que son el auténtico cimiento de la ciudad" (Sorkin 2004: 9), porque "se reduce todo vínculo con el espacio específico, con la geografía local, física y cultural" que definió la pertenencia (Sorkin 2004: 11). La percepción de la discontinuidad entre pasado, presente y futuro sin proyecto vital, y de la relación de independencia entre habitar y trabajar -a partir de la implementación de sistemas de turno que implican no residencia de los trabajadores en días de descanso-, es la constatación de la discontinuidad de la memoria, ya que ésta, en tanto autobiográfica, es por sobre todo un locus de experiencia patrimonial y de recreación del pasado, que es lo que permite atender y resolver en la contingencia e incertidumbre sobre el presente y el futuro.

Al estudiar este vacío en la comunicación intergeneracional y en la expectativa residencial generada en María Elena, que deja a muchos fuera de lugar, debemos necesariamente abrir la discusión de la memoria, la identidad, la representación y el patrimonio hacia el reconocimiento complejo de lo que cambia como fenómeno cultural y social.

\section{* Lo local y lo global en María Elena}

Con su capacidad técnica, la empresa SQM (propietaria de María Elena) se orienta hacia redes globales, y eso define de manera fundamental la relación de quienes habitan la ciudad con su territorio, su destino y las actuales formas específicas de sociabilidad que la diferenciaron respecto de otras unidades de pertenencia tanto internas como externas. Es en esta internacionalización de la empresa y en las nuevas reglas de eficiencia donde se desestima la memoria y la representación, al modificar la concepción de la urbe y su necesidad, debiendo asumir que María Elena tiene un lugar en una "cadena de posiciones" (Sassen 2007). Esta condición de lugar no la adquiere en tanto ciudad, sino en tanto campamento de trabajadores mineros, lo que se expresa en su actual patrón de asentamiento, con una nula oferta habitacional y particular demografía, en el que destaca el poseer la proporción más baja de personas mayores de 60 años dentro de las comunas del país (3.45\%) y un índice de masculinidad positiva y en aumento (116.34 en 1992 a 132.98 en 2002). ${ }^{4}$

Mirado así, el proceso de transformación, la imagen de la ciudad se elonga, se deforma y se vuelve refractaria respecto de su pasado (proyecto vital, vivienda, trabajo, alimentación, recreación, seguridad), al vincularse al menos con tres niveles de espacios económicos en esta cadena de posiciones:

1) El de la extracción primaria y procesamiento de la materia prima, que sigue teniendo como base la misma zona de operaciones y que puede realizarse prescindiendo de la ciudad y de gran parte de sus habitantes.

2) El de los servicios empresariales especializados locales y externos, que pueden ser convocados sin ser incorporados a la estructura de la ciudad.

3) El de relación y dependencia de los mercados financieros globales, que define una matriz de comportamiento económico y financiero flexible para la empresa y la envergadura de sus operaciones (Sassen 2007).

A partir de la relación entre estos niveles, la primera apreciación que podemos realizar en torno a la ciudad es la siguiente: las prácticas sociales que se dan en este interior urbano ya no son definidas solo desde una perspectiva nacional o local. No hay posibilidad de comprender el híbrido ciudad-campamento minero únicamente desde el punto de vista territorial, ya que hablamos de un "globalismo localizado", que se expresa como norma en procesos concretos de autorregulación, como la flexibilidad numérica y funcional de la fuerza de trabajo, en gran medida determinada por el proceso de internacionalización de la empresa y los imperativos transnacionales como eficiencia y rentabilidad.

\footnotetext{
4 Un importante análisis sociodemográfico sobre distintos indicadores comunales se encuentra en Mandujano (2007 Ms).
} 
SQM es líder en el mercado mundial de fertilizantes. Posee las mayores reservas a nivel mundial, tiene operaciones en los cinco continentes, con presencia en 22 países y venta en más de 100 naciones (Estrategia, 15 de noviembre, 2008). De este modo, el espacio económico que determina la condición existencial y de pertenencia de los habitantes de María Elena es de alta complejidad por su articulación con lo global, por lo que requiere de servicios adicionales (financieros, contables, logísticos) tanto nacionales como internacionales. Existen también otras cuestiones como las cotizaciones en la Bolsa de Comercio local o en la de Nueva York, y el interés del capital financiero por controlar la empresa, como también las asociadas a cadenas de operaciones como las faenas, embarques, distribución y transporte, o los mismos estudios de impacto ambiental, que hacen que el espacio geográfico del emplazamiento esté condicionado de manera directa e indirecta por otros circuitos y espacios económicos.

La extracción del nitrato y la elaboración de sus derivados es parte de circuitos globales especializados, pero también de circuitos nacionales y regionales (trabajo, operaciones y plantas). Es tal el tamaño de las operaciones y la magnitud de los recursos comprometidos, que el hecho de ser dueña del emplazamiento urbano, permite a SQM negociar con cierta discrecionalidad con el Estado a través del municipio y con empresas particulares sin contrapeso con los habitantes.

Como puede apreciarse, la interacción social al interior de María Elena está determinada por elementos exógenos, lo que se expresa en un recambio inducido de sus moradores, que pasaron de familias a individuos solos. Pero, más allá de las nuevas relaciones laborales, desde el punto de vista material, se mantiene como un complejo urbano uniforme y de interés patrimonial, ya que es parte de las ciudades del temprano capitalismo industrial chileno.

En este sentido, un avance más rápido o definitivo desde una ciudad hacia un campamento minero, se traba con el reconocimiento que adquiere por ser la "última" ciudad salitrera y la consecuente declaración de "zona típica" de una parte de sus inmuebles. Entonces, las faenas actuales se atraviesan con lo patrimonial, es decir:

“...sobre aquello que vehicula discursos sociales sobre la identidad colectiva, sobre la delimitación de las fronteras territoriales y sobre la posición de la comunidad imaginada en la Historia" (Iniesta 2009: 471).

Pero, ¿cuánto importa esto último en una comuna donde la variación intercensal cae entre 1992 y 2002 en $-44.9 \%$, y en la que se espera, según estimaciones del Instituto Nacional de Estadísticas de Chile (INE), que hacia el año 2015 su población llegue a unas 2706 personas? (Mandujano $2007 \mathrm{Ms}$ ). De otro modo, ¿son compatibles el desarrollo económico y financiero de una empresa internacionalizada con la mantención del patrimonio material de la ciudad y con los intangibles de la cultura?

Como ciudad, por su alto costo asociado a gastos no industriales, es incompatible con el desarrollo adquirido por los actuales asentamientos de trabajadores de última generación, adaptados, por ejemplo, a formas de trabajo flexibles, temporales o parciales, como se observa en los complejos de otras empresas mineras como Pabellón del Inca (Compañía Minera Doña Inés de Collahuasi, 1999), Los Pelambres (Compañía Minera Anaconda Chile, 2000) o San Lorenzo (Compañía Minera Escondida, 1995). Todos estos, con todo incluído, son de alta eficiencia y sin duda llegarán a convertirse en patrimonio por su estética, pero no tienen a sus espaldas familias, tradiciones, memorias y bienes en condición o en vías de patrimonialización.

La importante transformación laboral sufrida en general en la minería con sistemas all inclusive -como está ocurriendo en María Elena-, con sistemas de turnos y externalización de servicios, nos indica que con las nuevas fórmulas no hay adherencia simbólica y material al territorio, como ocurrió con esta ciudad salitrera, por lo que se trata exclusivamente de comunidades de trabajadores funcionales. Así, en María Elena lo antiguo es la materialidad del complejo, y lo nuevo, es el recambio de los trabajadores tradicionales por trabajadores "modernos y calificados" sin memoria material y simbólica del lugar, y sin memoria histórica de lo que significa el salitre para nuestro país. Así, el actual espacio de interacción se vuelve bricolage, y la imagen urbana muta por la integración de nuevos componentes externos. Este tránsito y diferenciación nos deja como tarea teórica y metodológica el desafío de representar la permanencia y adherencia de los trabajadores a unidades socioculturales, económicas y políticas que pueden ubicarse en diversos lugares. 
Analizando el cambio desde el interior, pero sin perder de vista la interpenetración de los espacios económicos ya señalados, reparamos en la aparición de nuevas reglas cinéticas introducidas por las redes de comunicaciones virtuales y fácticas. Se aprecia que los nuevos actores participan de "superlugares", llenos de nuevas cualidades estéticas, sociales e identificatorias. Los nuevos actores de la explotación del caliche y de la elaboración de sus derivados (litio, yodo, nitratos), se mueven en un espacio ilimitado, distinto al histórico local, lo que contradice uno de los rasgos más importantes de la cultura y del habitar la pampa de los trabajadores del salitre, en la medida en que los límites mentales estaban profundamente marcados por los límites de la Oficina (González 2002, 2006) o, en este caso, por los de la ciudad. Por tanto, lo que se altera es la relación entre la vida de los habitantes y las cosas que son propias del emplazamiento. Esto es, el estar en común, el pertenecer a un lugar donde los sistemas de reconocimiento se basan fundamentalmente en el sustrato territorial.

En este sentido, la resistencia identitaria que pudiese esperarse en torno al patrimonio simbólico, es decir, el recordar como memoria, la literatura que se edita, los $C D$ con imágenes y música que se producen, los objetos que se coleccionan, la celebración de ciertos rituales -como el $1^{\circ}$ de noviembre o el aniversario de Pedro de Valdivia- constituyen fenómenos recreados que están más allá de lo local.

Teórica y metodológicamente enfrentamos una pérdida de los sistemas descriptivos y representativos, asociados a la falta de relación entre los individuos y de los individuos con las cosas, que son parte de la urbe y de la vida cotidiana. Esto indica de manera evidente la condición de transición y no pertenencia, de precariedad y de ausencia de estabilidad en las relaciones sociales y en la vinculación con los espacios de la ciudad, marcando un profundo cambio en torno a cómo históricamente se invertía la vida de las personas en alimentar esa relación. En este sentido, la no necesaria adherencia territorial por la imposibilidad de plantearse un proyecto vital, introduce la obligación de imaginarse escenarios de sobrevivencia y de nuevos lugares donde volcar la experiencia y la memoria de un mundo de hombres y mujeres de la pampa que se extinguió.

Se trata esencialmente de hombres, mujeres y familias del presente, definitivamente consagrados/as a vivir la vida como viene: en una red deslocalizada e inestable. En este sentido, los trabajadores mineros y sus familias no son parte del futuro territorializado como lo fueron los antiguos con su proyecto de vida, lo que deja pocos márgenes para la memoria. Por eso, es una ciudad de la espera, y no de la esperanza, lo que reduce el patrimonio y la memoria a su expresión material.

Entonces, María Elena se empieza a convertir en un fantasma y en un "no lugar". En un espacio de ausencias y de crisis de representación, en la medida que la sociabilidad -como uno de los rasgos referenciales que permiten la identificación - se encuentra debilitada y que los marcos históricos de la experiencia en relación a las construcciones declaradas "zona típica" están en desuso. La ciudad-campamento no es más el lugar de las relaciones y la sociabilidad, ya que se debilita la importancia del estar ahí. Gran parte de los trabajadores mantienen una relación "atópica" con el lugar, en la medida en que el espacio no tiene significados, no hay lazos con él y solo ofrece una localización (Lindón 2005: 154).

Es necesario destacar, estratégica y metodológicamente, dos cuestiones. Por una parte, que hay una importante separación entre los espacios reales y la monumentalidad de la ciudad. Y, por otra, que se produce un tránsito desde una perspectiva monotópica a una politópica en relación a los desplazamientos. Metodológicamente, se demanda una observación del proceso desde varios lugares y movimientos simultáneos: salir y llegar, ir y venir, aquí y allá, pues se enfrenta una pérdida de referencias materiales y afectivas. Hay un paso hacia nuevas centralidades, y se produce una definitiva escisión del trabajo con su carga afectiva y épica especialmente por el proceso de obsolescencia del saber tradicional.

"El trabajo se ha convertido en algo precario, flexible, intermitente, con duración, horarios y salarios variables, el empleo deja de integrar en un colectivo, deja de estructurar el tiempo cotidiano, semanal, anual y las edades de la vida, deja de ser el zócalo sobre el cual cada uno puede construir su propio proyecto" (Gorz 2000: 67).

\section{* El sismo y la RUina}

Ya hemos observado y destacado algunos elementos importantes de un proceso de transición social y cultural en 
medio de volúmenes arquitectónicos patrimonializables, que va desde la ciudad utópica a la figura de un campamento minero. Por cierto, la nueva figura no está exenta de problemas que demandan resolución. Pero, aun cuando en toda ciudad la percepción no es continua sino fragmentaria (Lynch 2008), la condición específica de esta ciudad utópica y sus límites, especialmente definidos por regulación social y por el paisaje que demarca el asentamiento (lo que impidió otras actividades económicas), generó una importante homogeneidad e idea de totalidad que ayudó a fortalecer un sentimiento de pertenencia e identidad.

Sin embargo, pese al decline de la ciudad histórica, emerge desde esta dinámica una nueva ciudad: "la ciudad patrimonial", la ciudad única y distinta que hay que ver, la que se puede mostrar y quizá la que hay que salvar. Esta condición se ha precipitado por un importante terremoto que ha introducido un violento e inesperado nuevo eje a las variables sociales puestas en perspectiva como parte de esta transición, y de las cuales depende el futuro de la ciudad minera, sus habitantes y la posibilidad de habitarla. Un $80 \%$ de las construcciones ha sufrido serios daños y aproximadamente 300 casas han quedado inhabitables, por lo que muchas de ellas han debido ser demolidas.

El imprevisible sismo del 14 de noviembre de 2007 acelera la percepción de ruptura con el imaginario colectivo y precipita de manera manifiesta la ruina que era parte del paisaje del desierto, pero exterior a María Elena. Con la ruina se consolida la crisis de representación social al verse cuestionada y acelerada la imagen oscura del futuro como proyecto local; asoma una incertidumbre afectiva y cognitiva respecto del lugar a ocupar.

A partir del sismo, más allá de que el potencial habitacional de la ciudad se haya recuperado, la antigua ciudad se arruinó para las personas y no hay nada que hacer contra eso. Desapareció el hospital, una buena parte del barrio norteamericano se deterioró de manera irreversible, algunas casas irremediablemente ya no están frente a los ojos como tampoco corridas de viviendas familiares. Muchas de ellas correspondientes a la fundación originaria y sus habitantes, que pasaron décadas en ellas, ya no son parte del paisaje. En el mejor de los casos hay un reemplazo, una relocalización funcional de las casas pero, más allá de la decisión de recuperar lugares históricos, hay algo que ya no existirá. Se trata de lo que se perdió para siempre porque desapareció física y socialmente, y la intensidad de su recuperación no será más que simulacro desprovisto de su contenido existencial.

Los lugares habitacionales serán transformados con algunas nuevas construcciones. No existirá una recuperación, sino que se instalará una reconstrucción o una refundación que puede ser idéntica como maqueta. La aplicación del plan mantendrá lo que está definiendo el derrotero de la última ciudad del salitre: una geografía de la crisis y de la disolución de la interacción (Reguillo y Godoy 2005), y ahora habrá que pensar el pasado como producto. Se impone la lógica del individualismo y de la soledad en la nueva construcción, como puede apreciarse en el diseño de nuevos pabellones para trabajadores (Figura 2).

En las ciudades en decadencia son los viejos los portadores del mito de origen, así como de la narración que da pábulo al deterioro de la condición de vida que anuncia la ruina. De manera paralela, son los jóvenes los que incursionan en nuevas utopías, releen el mito de origen y exploran nuevos caminos que, en este caso, superan el espacio local; porque su vida no transcurre solo dentro de las estructuras preexistentes sino expresando maneras emergentes de sentir en común.

En las ciudades en decadencia las ruinas son importantes marcadores que operan como espejos y con los que se dialoga, ya que toda relación social se establece tanto al pasado como al presente de manera cronotópica y se consolida como una cultura que ha sido trabajada en la historia a la par de las improntas y huellas materiales. Son las ruinas de María Elena las que hablan a sus habitantes de un pasado y un proyecto trunco. La ruina indica un modo de estar $y$ hacer ciudad. Se trata de galpones y edificios sin utilidad, cines sin proyecciones, salones de baile sin música, sedes sindicales sin trabajadores, maquinaria incompleta, estaciones de ferrocarril abandonadas, material rodante en desuso, barrios enteros deteriorados, o intervenciones urbanas inarmónicas, lo que delata el quiebre temporal y la falta de continuidad de un proyecto de vida urbana asociada a actividades económicas específicas (Signorelli et al. 1999).

Las ruinas expresadas en edificaciones otrora significativas y fundamentales, recuerdan la inmensidad de la historia y el tiempo, pero, a la par, expresan el propio 


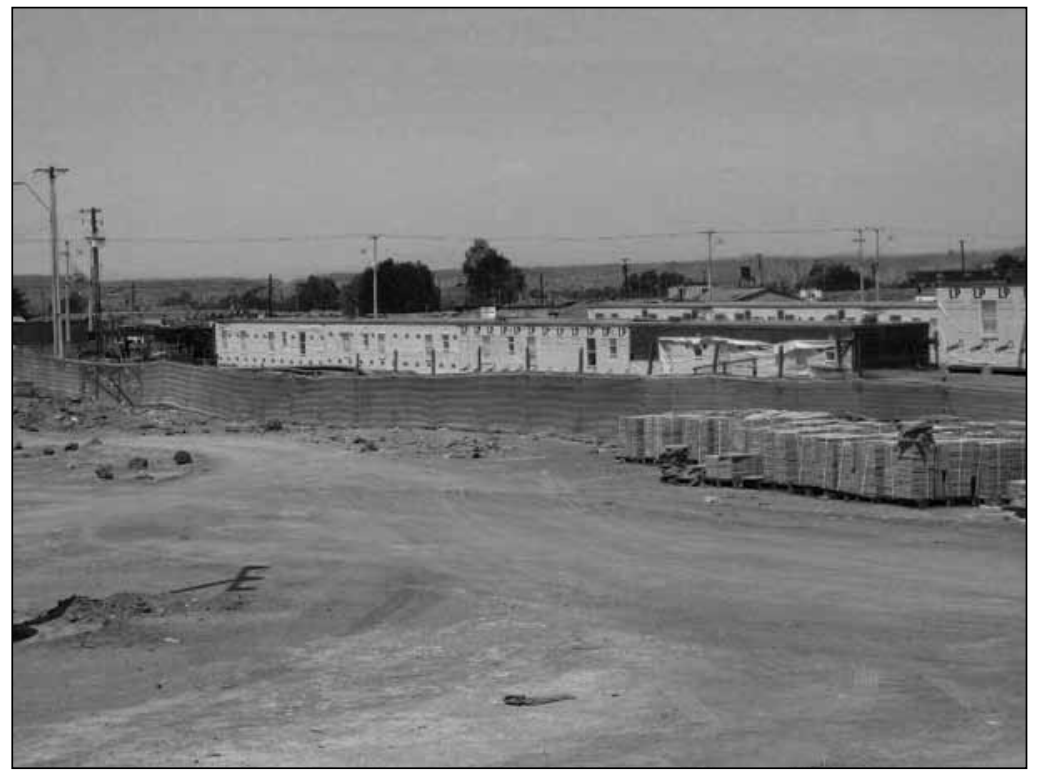

Figura 2. Actuales construcciones para los trabajadores. Fotografía de Fernando Mandujano.

deterioro de sus habitantes y la insignificancia de las posibilidades de seguir viviendo en María Elena. La ciudad ya no encanta, pierde su espesor y su imagen de futuro es más remota y pobre, y se convierte en una anotación en el territorio tal como se han convertido las otras oficinas y ciudades del salitre.

Las ruinas como trayectoria en María Elena, deben ser pensadas como acontecimientos que hablan y se refieren a momentos en los que se transita por un desequilibrio entre lo colectivo y lo individual, y que son verificables en tanto son visibles y localizables en el espacio urbano. Refieren a lo que sucede o ha sucedido, y se alzan en un momento como un fragmento de realidad percibida y vivida por algunos, y que se anuncia hoy como parte de una existencia irregular o en declinación. De este modo, el interés y la opción por la patrimonialización de la ciudad constituye en un nuevo despertar de la memoria a partir de la ruina. Esto sería una posible salida que resuelve la pregunta sobre el destino y futuro material de la ciudad, y el lugar de las experticias de sus viejos habitantes, como un proceso de arqueologización de sus vidas.

Entonces, como ciudad única por sus características inicialmente utópicas, pero por sobre todo representativa del capitalismo industrial, la cuestión es cómo manejar el deterioro provocado por un cierto abandono y por el sismo, a la vez que consolidar la política de transformación de ciudad a campamento que se liga al objetivo empresarial. ${ }^{5}$ Se instala el qué proteger, con qué objetivo y con qué mirada, aun cuando el evento telúrico no hace sino reforzar la experiencia del convivir con la ruina a la que se habían acostumbrado los habitantes. Ruina proyectada en el tiempo, en la medida que la política de la empresa SQM desincentivó la inyección de recursos en la mantención de la infraestructura comunitaria y subsidios (goce de vivienda, y liberación de importe de luz y agua potable), para arrastrar la condición de ciudad a su condición mínima de funcionamiento y así cumplir con sus objetivos productivos, y debilitar las expectativas de sus habitantes.

De este modo, la ruina se presenta de varias formas simultáneas, lo que conceptualmente es muy potente desde la perspectiva de la recepción del hablante y de un habitante que mira con desdén el ayer y el presente. Por cierto, la ruina está asociada al "estar arruinado", y por eso, la ruina connota más allá de su denotación, pues detrás de ella hay una emoción, un sentido muy subjetivo que

5 El sismo afectó tanto a las familias residentes como a las instalaciones donde pernoctan trabajadores y los de la propia empresa que operan bajo el sistema de turnos. 
arrastran sus habitantes. La ruina simultáneamente es sinónimo de empobrecimiento, adversidad en cuanto sistema de oportunidades, y sentido de abandono en términos arquitectónicos, que es lo más evidente cuando se recorre la ciudad. De manera concreta, ante esta "herida" (Edensor 2005), la noción de patrimonio se presenta como recurso ideológico y también como una salida económica.

El proceso descrito es muy coincidente con la propuesta de Debord (1995), en cuanto la declinación del valor de uso en los marcos del capitalismo, genera condiciones para que ese valor se transforme en valor de cambio, al hacerlo entrar en los marcos de una sociedad del espectáculo. Más específicamente, el entrar en un proceso de mercantilismo de la memoria, porque las ruinas industriales se venden como una mercancía, son externalizados los eventos memorables, los lugares y los objetos; se produce una mediatización de los símbolos populares, mitos e íconos fuera de la comunidad local. Toda la vieja historia es presentada como parte de un exótico particularismo local (Ederson 2005: 126).

Lo patrimonial es la pura materialidad que no puede dar cuenta de las maneras de vivir en el espacio urbanizado. Esto significa que esa parte material ha entrado en la historia, indicando una crisis y disolución de algunas o todas las interacciones en torno a ella, en la medida que la disfunción se empieza a constituir en un producto, y a circular como una mercancía que busca a hombres y mujeres que desean tener experiencias (Pine y Gilmore 1999). Es decir, se imponen imágenes-objetos ante los consumidores, por lo que podríamos decir, que entramos en los marcos de las representaciones y de los simulacros.

La estrecha noción de patrimonio no hace más que marcar elementos materiales, pues los intangibles de la cultura tienen un valor secundario o se invisibilizan, o definitivamente son irrecuperables. El interés por la "ruina", claramente, tiene una existencia independiente de las personas que puedan deambular en medio de las ciudades patrimonio o que quieren ser presentadas como patrimoniables. Entonces, dentro de una economía de la experiencia, su despliegue permite definir distintos niveles de satisfacción: a) educativas, que son propiciadoras de un aprendizaje; b) escapistas, que tienen que ver con el hacer; c) entretenimiento, asociadas al sentir, y d) contemplativas, ligadas al "estar ahí", y al construir una red de asociaciones libres (Pine y Gilmore 1999).
Entonces, la experiencia "patrimonial" se mueve dentro de los intersticios del capitalismo, como una habilitación de nuevos espacios de desarrollo de la última ciudad del salitre.

"El recuerdo necesita de superficies de inscripción donde grabarse para que la relación viva entre marca, textura y acontecimiento, libere nuevos efectos de sentido" (Richard 2001: 15).

Patrimonializar es un nuevo sentido y despertar de la ruina, es refuncionalización de un uso inscrito en una nueva lógica de la cual puede apropiarse la economía de la experiencia, ubicándola más allá de sus límites espaciales, su historia y sus posibilidades.

Es la "ruina" la que entra en el patrimonio, la que da cuenta de un quiebre, de un trauma, de una actividad que queda en el olvido. Se trata de reconocimientos que ya no están, de oficios que se pierden en el tiempo, de una necesidad que ya no tiene su lugar, del deterioro de la condición de vida, de la pérdida de solidaridad colectiva, de un habla que se convierte en anecdótica, de una forma de sentir, de una desintegración de la comunidad.

\section{* El problema patrimonial en María Elena}

Hay un criterio en la administración de la ciudad campamento que es empresarial, pero que no puede sacudirse de lo simbólico. Existe una tensión entre lo meramente económico y lo simbólico, donde lo primero tiene un límite moral que está dado por lo simbólico, ya que resultaría impresentable social y culturalmente para una empresa de alta eficiencia y de grandes utilidades, terminar por despoblar la ciudad en su conexión con la historia del salitre, o abandonar la iglesia, el teatro, la sede sindical como patrimonio material de esa, "la última ciudad" del salitre. Aunque la ciudad le pertenece materialmente a la empresa que hoy es minera más que salitrera, simbólicamente le pertenece a una memoria que es más amplia y que sobrepasa a lo local y a la administración. Evidencia de ello, es cómo la vecina ciudad de Pedro de Valdivia (cerrada y abandonada en 1996), que es simultáneamente ruina y patrimonio, es capaz de aglutinar ritualmente en su aniversario no solo a sus propios habitantes y su descendencia, sino a miles, como un pueblo que opera metonímicamente 


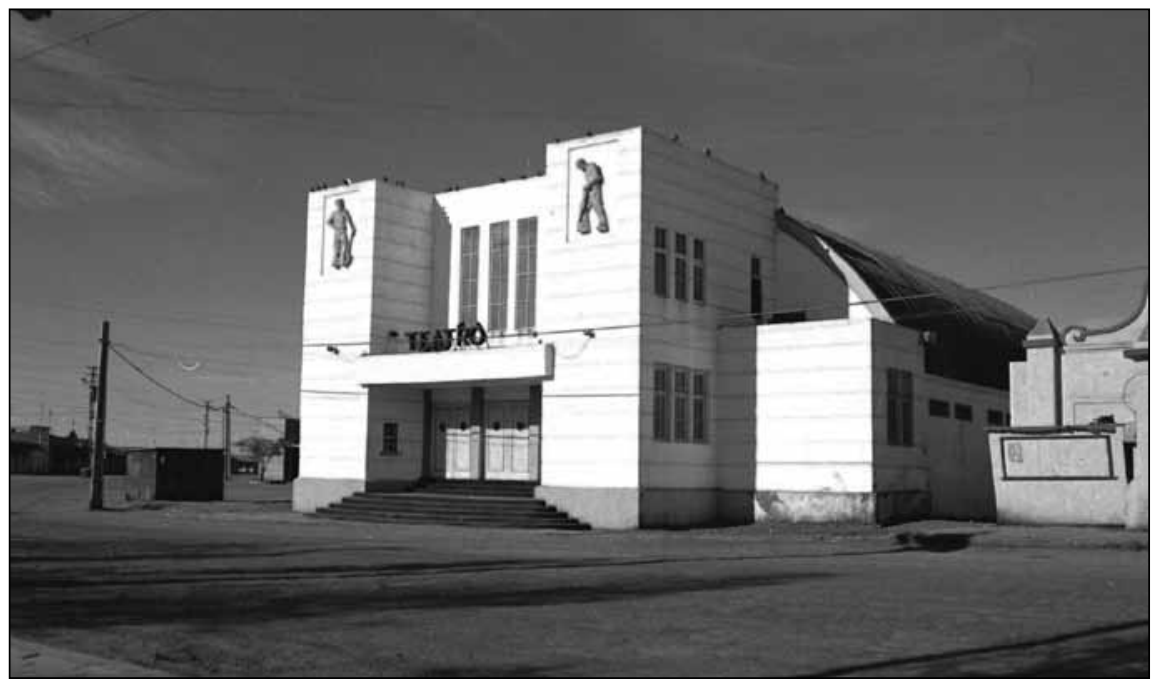

Figura 3. Teatro de María Elena. Fotografía de Isabel Zambelli.

como la representación de la vida pampina y salitrera en su totalidad.

La diferencia está en que Pedro de Valdivia no era la última ciudad. Era la penúltima. Su cierre la convirtió en lugar de peregrinación. La ciudad de María Elena es y no es; tiene algo de un pasado "relicto", pero también es futuro (campamento). La cultura pampina y su relato mítico está ahí entre los que no se han ido o no tienen dónde ir; pero también están los nómades no asociados al lugar ni a la historia, y que son también el presente y el futuro, y cuya visión es una mezcla de ignorancia y de desinterés. La ciudad campamento no es lugar para los "otros", para la continuidad y la memoria. Es solo tránsito. No hay casas, hay piezas, hay hoteles; no hay ranchos, hay casinos; no hay alimentación pampina, hay salad bar. Entonces, también tenemos un teatro que no funciona como teatro, una escuela consolidada que no es escuela (y que fue "conventillo"), una pulpería que no es pulpería, un mercado que no es mercado, y un habitante de la pampa que no es pampino sino minero (Figura 3).

\section{Como señala Melgar:}

"Dicho de otra manera, procedemos a apropiarnos de algunos bienes culturales, originariamente ajenos al resituarlos, revalorarlos, resignificarlos e incorporarlos a nuestro consumo cultural local o nacional" (2002: 53).
Solo que la reconstrucción y recuperación de parte de las materialidades no llega a temporalizar el espacio social, ya que no logra sobrevivir la experiencia. No hay continuidad entre pasado, presente y futuro, y en ese sentido hay una afasia, que podrá ser llenada con el relato histórico que constituye otro tipo de memoria. ${ }^{6}$

Allegar recursos por parte del Estado y la empresa a la reconstrucción de la ciudad, es acercarse a la figura de un parque temático, que no es más que "una rapsodia de la relación entre el transporte y la geografía" (Sorkin 2004: 235-236) dentro de los marcos de la "economía de la experiencia” (Pine y Gilmore 1999).? Lo único verdadero son los edificios que aún quedan en pie, ya que desde el punto de vista humano y laboral se aprecia el surgimiento de una nueva población sin arraigo alguno con el lugar, en medio de una zona declarada como "típica". Nos enfrentamos a una materialidad que hace sentir el vacío.

6 En un trabajo anterior (Rodríguez et al. 2002). hemos desarrollado otras formas de expresión de la memoria, refiriéndonos a su fórmula arqueológica, histórica, mítica, documental y utópica, desarrollando aspectos simbólicos y materiales alusivos a la identidad y a los ángulos de lectura y expresión del mundo de la pampa.

7 Para una reconstrucción de la ciudad se habla de una inversión de aproximadamente 8 mil millones de pesos chilenos, incluyendo recursos municipales, recursos fiscales del Fondo de Desarrollo Regional y de la empresa SQM. 
De este modo, el problema es cómo conciliar tradición y modernidad, o la ciudad con las exigencias de un campamento minero. Son casi 90 años de historia que deben compatibilizarse con la necesidad de una empresa minera moderna, eficiente y globalizada.

La primacía de hacer estético el pasado impide el ejercicio de memoria en el marco de las relaciones locales. La experiencia como ejercicio de enlace generacional y de transmisión de aquello que recorre la existencia, al quedar atrapada en la imagen de lo inmueble, debilita la relación analítica y crítica sobre el pasado, que es lo importante desde el punto de vista de la comprensión y el pensamiento. La estetización del pasado apuesta a reforzar la discontinuidad de la memoria, por lo que constituye un nuevo marcador de la ciudad que se anuncia. Como sostiene Cruz (2005: 70), la memoria ha sido desactivada y ha dejado de pertenecernos. La estetización instala un horizonte problemático ligado a la semejanza (Halbwachs 2004) y al auditorio (Agamben 2004), ya que deja por resolver cómo llega o se proyecta la materialidad en una ciudad campamento donde desaparece el rasgo más consistente que la definió como urbe: la intensa sociabilidad e identidad ligada a un tipo particular de trabajo y a una carga épica y mítica dentro del paisaje del desierto.

Entonces, ¿sobre qué huellas se erige el patrimonio cultural? ¿cuál es la selección de las fuentes? Y, lo más importante: ¿qué es lo que se omite? Si la historia recupera lo que ya no es, lo que ya no existe, ¿qué es lo que se representa a través de la recuperación de los inmuebles? ¿emocionalmente quiénes estarán conectados con ello? ipara quiénes se están haciendo? ¿se trata de un nuevo parque temático como parte de una ruta turística? Estas preguntas son válidas, pues, cómo sostiene Bauman (2006: 103-105), se trata de un mundo - para la mayoría- en movimiento e ilimitado, de turistas, vagabundos y viajeros conectados, aun cuando estemos en reposo. María Elena puede ser parte de esta red de sitios que permiten entrar a otro tiempo, aunque por cierto, simulado.

Puede ser arriesgado y peligroso hacer coincidir el patrimonio cultural y los bienes culturales exaltados solamente con materialidades (cosas, objetos, monumentos), en la medida que la excesiva mitificación del pasado puede quedar atrapada en la ilusión de algo que está muerto, y la misma historia y la arqueología serán cómplices de ese pasado muerto. El patrimonio cultural tiene que ver también con la comunicación: con la fuerza de los acontecimientos que recorren la memoria, con el reconocimiento de lo diverso y múltiple de las tradiciones, con los movimientos, los pensamientos disruptivos, las insurrecciones y las protestas. Si la imagen e identidad se aglutina solo bajo la materialidad de los monumentos, se omite la contradicción, el pensamiento crítico, las encrucijadas, las iluminaciones, el particularismo y el sentido de lo local, se configura el simulacro y se desvinculan las materialidades y las correspondencias con espacios concretos.

\section{* La ciUdad Patrimonializada}

El patrimonio corresponde a una imagen que permite que los ciudadanos tengan un cierto sentido de continuidad, observando los elementos de una trayectoria en común. Es decir, el patrimonio es la extensión de sí mismo o de lo que está más allá de sí mismo, pero como parte común, como legado de aquello que se reconoce como propio. Nos indica que hubo otros antes que nosotros, que nos legaron una cierta experiencia, y otros que nos sucederán. Ese enlace particular da cuenta de la identidad y la articulación entre generaciones. Por tanto, no se trata solo del pasado, se trata también del futuro, de la mediación de aquello que se resume o asume como propio, de una relación espacial con aquello donde se realizan las prácticas fundamentales y recurrentes de una comunidad.

Enfrentado de este modo el proceso de conciliación entre ciudad campamento y ciudad-campamento-patrimonio, lo que llamamos patrimonio es una huella, un rastro, es experiencia de vida expresada en cartografía y puntos nodales con los que estamos familiarizados. Es también memoria individual y colectiva. Es una representación del tiempo en la que la experiencia personal se liga con la estructura de su sociedad, pues con la memoria se recuperan los eventos a través de distintos soportes, se instauran presentes relativos, formas de diálogo, redes de sitios y relaciones de pasados inconclusos, provisionales, discutidos y discutibles; referenciales al tiempo vivido y no vivido (Rodríguez et al. 2002) (Figura 4).

Entonces, con la patrimonialización como acción social y política, ¿a qué pasado se quiere traer o recuperar? ¿a 


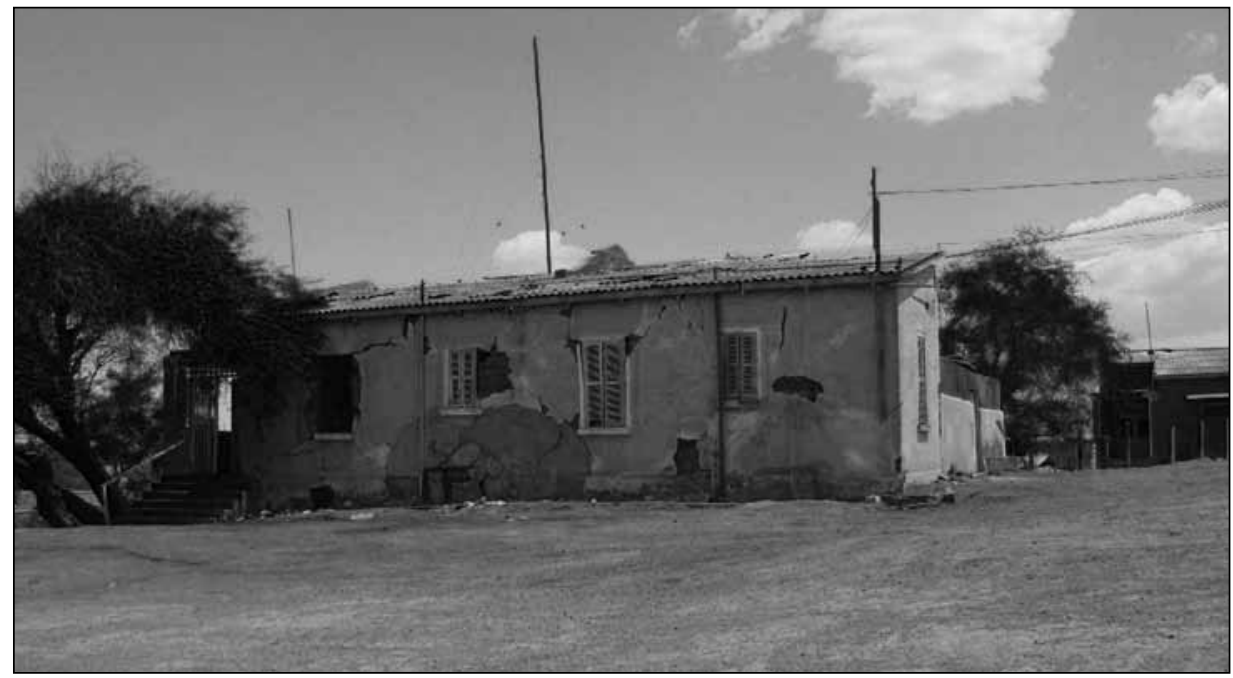

Figura 4. La "ruina" en María Elena. Fotografía de Fernando Mandujano.

qué memoria se quiere dar paso?, a la chistórica? ¿mítica? ¿utópica? ¿arqueológica? Independientemente de estas memorias como recuperaciones, lo seguro es que con el posible rescate de algunos bienes inmuebles que corresponden al entorno de la plaza y los lugares inmediatamente adyacentes, se da paso a un proceso de remitologización de la ciudad y a una ruptura -como sostiene Jameson (1991) - de nuestra tradicional experiencia de la temporalidad. Esto, sin duda, puede dar paso a la narración de diferentes ciudades: la ilusoriamente vivida, la sincrónica, la de la esperanza, la mítica, o la invisible.

Aquí, por cierto, enfrentamos dos cuestiones problemáticas a las cuáles se debe poner atención. Por una parte, la protección de la herencia del pasado frente a la cultura viva; $y$, por otra, como extensión de esta fórmula, el posible paso al pastiche insulso, en la medida que se impone la recuperación como subsidiaria de una tergiversación del pasado y sus vicisitudes, pues la cultura mítica y épica es residual.

La reflexión es importante, ya que lo que caracteriza a la ciudad campamento es el vaciamiento de su memoria a través de un nuevo régimen laboral, y la ausencia, como posibilidad, de proyecto vital para las familias que sobreviven a los cambios. A partir de la ruptura con la trama de la memoria, se trata de recuperar para mostrar, más que para vivir estos marcadores previamente seleccionados.
De este modo, la ciudad patrimonializada, o el interés por patrimonializarla, es también un recurso por estetizarla y convertirla en una mercancía, como muchas otras ciudades que se enfrentan a la declinación. Así, en este proceso hay dos cuestiones que son menester diferenciar: lo común y lo colectivo. Lo común se encuentra más bien ligado a un proceso de institucionalización de lo que debe ser mostrado, por lo que tiende a la homogeneidad y se constituye en memoria sesgada, al instalar una memoria posible sobre lo que debe ser relevado. En tanto, lo colectivo refiere a una memoria que recoge la experiencia de lo microscópico, de la red cotidiana, de lo heterogéneo y plural de la ciudad vivida por generaciones; se trata de una forma de situarse, vivir y aprehender el espacio.

De acuerdo a lo señalado, si hablamos de la ciudad que se abre a la patrimonialización, es porque hay un interés y una gestión que puede hablar en esos términos. Así, la figura de patrimonio es coherente con el paso de ciudad a campamento, porque esta última presupone la discontinuidad de la microhistoria que admite lo cotidiano en su enlace pasado-presente-futuro; es decir, se enfrenta el fin de la ciudad viva para dar paso a la ciudad del recuerdo, del documento, de la historia y de lo museable como estrategia política, quizá también del espectáculo como imagen de lo que algún día fue; también de un lenguaje para su muerte y resurrección. 
Esta operación simbólica fosiliza el cuerpo social, elude los conflictos y las inseguridades permanentes, esconde a las periferias que ha creado, y se sustrae e invisibiliza a las otras memorias. Entonces, por ejemplo: icuál es el lugar de los viejos saberes y el valor del sindicato?, ien qué quedaron los días de huelga y la olla común? Nada de esto en un tiempo más podrá ser registrado, ni podrá sobrevir a la amalgama funcional de ciudad-campamentopatrimonio; la nueva estructura urbana y funcionalidad no requiere ni del pasado ni de la historia. Solo basta esta artificialización de la memoria, y el recuerdo para transformarla en un cuadro turístico.

La paradoja es que el patrimonio, como estrategia, promueve puntos de encuentro, de memoria, de referencias y referentes comunes. Pero, en este esfuerzo, el hombre y la mujer quedan fuera, porque han sido despojados de sus certidumbres básicas y seguridades emocionales en su relación con el pasado, y especialmente con su futuro. La valorización patrimonial como estrategia aleatoria de sustentabilidad social del enclave minero, en su interés por recuperar parte del complejo inmobiliario, no está asociada a la calidad de vida de las personas ni a hacer más habitable y vivible María Elena. Es funcional a los cambios tecnológicos, al predominio del capital financiero por sobre el productivo, a la división internacional del trabajo y al nuevo orden mundial, así como a una estrategia para hablar de la diversidad.

En relación a ello, señala críticamente Melgar:

"Bajo las actuales circunstancias, resulta obvio señalar que el patrimonio cultural se presenta como un campo de disenso y de conflicto sobre sus usos económicos y simbólicos, que eufemisticamente aluden al Estado y la sociedad civil, desdibujando a sus actores sociales reales y sus intereses particulares y o colectivos (locales, nacionales o transnacionales), así como sus respectivas filiaciones etnoculturales y clasistas" (2002: 51-52).

La patrimonialización es una salida neoliberal frente a las periferias que ella misma ha creado. Valparaíso (actividad portuaria), Lota (centro carbonífero), Taltal (pequeña minería), entre otras, son ciudades que avanzan en la misma dirección; solo que María Elena posee una escala más manejable desde el punto de vista urbanístico y demográfico.

Cuando ya queden únicamente miradas apagadas, la estetización del pasado a través de la patrimonialización y la declaración de "zona típica" solo será una operación de hegemonía cultural. Está fórmula no es más que la pérdida de historicidad y de que "sacralizar la memoria es otra forma de hacerla estéril” (Todorov 2000: 33).

\section{* Al cierre}

La epopeya del salitre y su épica es una comarca de inmensa memoria que se puede escribir desde distintos lugares. La tarea es cómo inventar un lenguaje que restituya la imagen más pura, la más intensa, la que recupere los códigos comunes del universo cultural y moral de la última ciudad del salitre. ¿Cómo hacer revivir intensamente una ciudad en los distintos pliegues y relatos, cuando ya no puede verse todo, oírse todo e imaginarse todo? Es un tiempo donde los efluvios del habitar ya no pueden sentirse con intensidad; el cuerpo que se abraza ya no es el mismo, porque los átomos que lo componen en el tránsito ciudad-campamento-patrimonio cambiaron más allá de lo que la memoria puede resistir.

El modelo de hacer negocios y ser competitivos, junto con la vehemencia de la naturaleza comienza a arrastrar otra vez más la vida hacia los bordes, tal como ha sido el destino trágico del salitre. La ciudad ya no pertenece ni a su pasado ni a su presente, es como la luz cruda de la muerte. Ha perdido su vitalidad y encanto que alguna vez le hizo ser apreciada como la "buena moza de la pampa"; se ha convertido en ausencia y materialidad; su señorío guiña desde lejos, cada vez más alejado de su cuerpo. Para nosotros, la transformación de ciudad en campamento es la muerte que amenaza; es una cuestión de distancia, de tiempo de lo que queda por recorrer, para que nadie con la calidad de testigo pueda recordar. Las marcas de la cultura y del imaginario que la sostuvo se hacen poco a poco invisibles, como una experiencia simplificada e higienizada.

En la ruina, para algunos, se puede ver toda la vida pasar frente a los ojos. Para otros, solo podrá ser compatible con las fotografías que circulan y se reproducen de "otros tiempos", quizá cuando estaban "los gringos". El juego entre la evocación y el presente es contradictorio, fragmentario, bello y caótico, infausto y poético, glacial y febril, incierto y desgarrado, pero para todos los que conforman la periferia de la urbe y los que con dolor se han 
ido de ella -al menos físicamente-, es de reaprendizaje, de reescritura biográfica y de diseminación de la memoria.

En medio de la ruina el silencio es el ruido más fuerte, quizá el más fuerte de todos los ruidos que puedan oírse. En parte, la decadencia que implica la ruina, constituye simultáneamente la vida y su horizonte trágico: el mundo que se fue para siempre. La reconstrucción de María Elena y la recuperación de algunos edificios nos ponen en el camino de un lugar que no podemos visitar como territorio vivo, porque ya no se puede tener experiencia de ello. En palabras de Sorkin (2004: 236), "hay una imposibilidad de estar presente en la escena evocada", por lo que se desliza con fuerza la distinción entre memoria e historia, en la medida que el relato vivo ya se encuentra agónico y no logra diseminarse en su interior.

La historia, de acuerdo a Halbwachs (2004), comienza donde la tradición termina, cuando la memoria social se descompone, se fractura y se debilita. La historia privilegia objetos que son legítimos de los que no lo son, jerarquiza, excluye, construye explicaciones. Cuando un relato está vivo, es inútil tratar de fijarlo porque su cualidad es la movilidad en el espacio y el tiempo; y lo colectivo, reside en comprender el sentido de esos ecos cotidianos y leerlos adecuadamente. A veces, la parte siniestra de la vida, la ruptura con los proyectos esenciales y vitales, arrastra la memoria a otros derroteros.

Como se ha señalado, los cambios estructurales ocurridos en el ámbito del trabajo impactan en el territorio y en los proyectos vitales de las personas, ya que las determinaciones sobre las propias vidas son cada vez más exiguas. Pero estas transformaciones son decisivas si se trata de evaluar y dar cuenta de la génesis, el desarrollo y el cambio del saber tradicional en una cultura laboral del desierto, hoy agónica. El patrimonio material, que es lo que se puede contener y preservar, ya que los intangibles se han diseminado, no puede restituir los intersticios de la vida de este company town, de lo que fue la construcción de la producción del saber y la semejanza que moldeó a sus habitantes.

La ciudad, o lo que queda de ella, se mueve solo con criterios administrativos funcionales. No hay masa crítica que piense la ciudad desde su interior, como habitantes.

El trabajo de los antropólogos en este espacio nuevo de enunciación retórica, mezcla de patrimonio material y de parque temático, de nostalgia y pragmatismo, debe escuchar el silencio que se esconde y reinterpretarlo; sentir el vacío y asumirlo como sino inevitable del cambio y de lo que deja de estar para no regresar. En definitiva, hay un nuevo desafío: icómo hacer que el silencio de la materialidad se vuelva espeso y presente?

Como en muchas ciudades, el destino de María Elena está cruzado por el atractivo que puede tener para sus habitantes o para el turismo. Mientras, la ruina sigue penetrando para hacerla morir, y en nombre del silencio, de los gritos y murmullos ahogados, el cielo seguirá sin nubes y nadie jugará bajo el sol.

\section{* Referencias citadas}

AGAMBEN, G., 2004. Infancia e historia. Adriana Hidalgo Editora, Buenos Aires.

ANDERSON, B., 2002. Las comunidades imaginadas. Fondo de Cultura Económica, México D.F.

AUGE, M., 2008. Globalización, mediatización, urbanización; travesías y ficciones de la antropología. En Política, ficción, subjetivación: Figuras de lo humano, A. Bilbao y P. Vermeren (Eds.), pp. 41-47. Ediciones Universitarias de Valparaíso, Valparaíso.

BAUMAN, Z., 2004. La globalización. Consecuencias humanas. Fondo de Cultura Económica, Buenos Aires.
BANCHS, M., A. AGUDO y L. ASTORGA, 2007. Imaginarios, representaciones y memoria social. En Espacios imaginarios y representaciones sociales. Aportes desde Latinoamérica, A. Arruda y M. de Alba (Eds.), pp. 47-95. Editorial Anthropos, Barcelona.

CASQUETE, J., 2008. Calendario y memoria colectiva. Anthropos 218: 110-119.

CASTORIADIS, C., 1981. L'Institution imaginaire de la societé. Seuil, París.

CERTEAU, M. DE, 1999. La invención de lo cotidiano. Habitar, cocinar. Editorial Universidad Iberoamericana, México D.F. 
CRUZ, M., 2005. Las malas pasadas del pasado. Identidad, responsabilidad, historia. Editorial Anagrama, Barcelona.

DEBORD, G., 1995. La sociedad del espectáculo. Editorial La Marca, Buenos Aires.

EDENSOR, T., 2005. Industrial ruins. Space, aesthetics and materiality. Berg, Oxford.

ESTRATEGIA. EL DIARIO DE NEGOCIOS DE CHILE, 2008. Noviembre 15 .

GARCÉS, E., 1999. Las ciudades del salitre. Editorial Orígenes, Santiago.

GARCÉS, E., M. COOPER y M. BARROS, 2007. Las ciudades del cobre. Ediciones Universidad Católica de Chile, Santiago.

GONZÁLEZ, S., 2002 Hombres y mujeres de la pampa. Tarapacá en el ciclo de expansión del salitre. LOM Ediciones, Santiago.

2006. El mundo de las casas de lata. La vida en la pampa salitrera. En Historia de la vida privada en Chile. El Chile moderno de 1840-1995, R. Sagredo y C. Gazmuri (Eds.), pp. 187-213. Editorial Taurus, Santiago.

GUMUCHIAN, H., 1991. Représentations et aménagement du territoire. Editorial Anthropos, París.

GORZ, A., 2000. Miserias del presente, riqueza de lo posible. Paidós, Buenos Aires.

HALBWACHS, M., 2004. La memoria colectiva. Prensas Universitarias de Zaragoza, Zaragoza.

INIESTA, M., 2009. Patrimonio, ágora, ciudadanía. Lugares para negociar memorias productivas. En El Estado y la memoria. Gobiernos y ciudadanos frente a los traumas de la historia, R. Vinyes (Ed.), pp. 467-498. RBA Libros, Barcelona.

JAMESON, F., 1991. El posmodernismo. La lógica cultural del capitalismo avanzado. Paidós, Barcelona.

LINDON, A., 2005. Figuras de la territorialidad en la periferia metropolitana: Topofilias y topofobias. En Ciudades translocales: Espacios, flujos y representación. Perspectivas desde las Américas, R. Reguillo y M. Godoy (Eds.), pp. 145-172. Instituto Tecnológico de Estudios Superiores y Social Science Research Council, México D.F.

LYNCH, K., 2008. La imagen de la ciudad. Editorial Gustavo Gili, Barcelona.

MAISONNEUVE, J., 2005. Las conductas rituales. Nueva Visión, Buenos Aires.

MANDUJANO, F., 2007 Ms. El rol de la escuela en el último pueblo salitrero: Estudio descriptivo y prospectivo de la educación en
María Elena, región de Antofagasta. Tesis de Magíster en Administración Educacional. Universidad de Playa Ancha, Valparaíso.

MARTÍN, F., 2007. El lugar de la bifurcación. En Antropología del desierto. Paisaje, naturaleza y sociedad, R. Pérez-Taylor, M. Olmos y H. Salas (Eds.), pp. 15-33. Universidad Nacional Autónoma de México, México D.F.

MELGAR, R., 2002. Globalización y cultura en América Latina. Crisis de la razón y de la axiología patrimonial. En Antropología y complejidad, R. Pérez-Taylor (Ed.), pp. 49-66. Gedisa Editorial, Barcelona.

REGUILLO, R. y M. GODOY, 2005. Cartografías urbanas desde las Américas. Una introducción posible. En Ciudades translocales: Espacios, flujos y representación. Perspectivas desde las Américas, R. Reguillo y M. Godoy (Eds.). Instituto Tecnológico de Estudios Superiores y Social Science Research Council, México D.F.

RICHARD, N., 2001. Residuos y metáforas. Ensayos de crítica cultural sobre el Chile de la transición. Editorial Cuarto Propio, Santiago.

RODRÍGUEZ, J. C., 2007. Duelo y sentido de lo trágico en la tierra del nitrato. Los últimos trabajadores del salitre buscando un lugar. En Antropología del desierto. Paisaje, naturaleza y sociedad, R. Pérez-Taylor, M. Olmos y H. Salas (Eds.), pp. 247-28o. Universidad Nacional Autónoma de México, México D.F.

RODRÍGUEZ, J. C. y P. MIRANDA, 2008. Tiempo industrial y tiempos sociales en María Elena, la última ciudad del salitre. Chungara, Revista de Antropología Chilena 40 (1): 81-97.

RODRÍGUEZ, J. C., P. MIRANDAy P. MEGE, 2002. Etnografía de la Siberia Caliente. Una nota metodológica sobre un estudio en María Elena, el último pueblo salitrero. Estudios Atacameños 22: 105-126.

PINE, B. J. y J. H. GILMORE, 1999. The experience economy. Work is theatre and every business a stage. Harvard Business Press, Harvard.

SASSEN, S., 2007. Una sociología de la globalización. Katz Editores, Buenos Aires.

SIGNORELLI, A., N. GARCÍA CANCLINI y R. NIETO, 1999. Antropología urbana. Anthropos Editorial, Madrid.

SONTAG, S., 2006. Sobre la fotografía. Alfaguara, Buenos Aires.

SORKIN, M., 2004. Introducción: Variaciones sobre un parque temático. En Variaciones sobre un parque temático. La nueva ciudad americana y el fin del espacio público, M. Sorkin (Ed.), pp. 9-14. Editorial Gustavo Gili, Barcelona.

2004. Nos vemos en Disneylandia. En Variaciones sobre un parque temático. La nueva ciudad americana y el fin del espacio público, M. Sorkin (Ed.), pp. 231-257. Editorial Gustavo Gili, Barcelona.

TODOROV, T., 2000. Los abusos de la memoria. Editorial Paidós, Barcelona. 